\title{
Assessment of Soil Erosion and Climate Variability on Kerio Valley Basin, Kenya
}

\author{
Mark K. Boitt*, Oburo M. Albright, Harison K. Kipkulei \\ Department of Geomatic Engineering and GIS, Jomo Kenyatta University of Agriculture and Technology, Nairobi, Kenya \\ Email: *mboitt@jkuat.ac.ke
}

How to cite this paper: Boitt, M. K., Albright, O. M., \& Kipkulei, H. K. (2020). Assessment of Soil Erosion and Climate Variability on Kerio Valley Basin, Kenya. Journal of Geoscience and Environment Protection, 8, 97-114.

https://doi.org/10.4236/gep.2020.86008

Received: February 2, 2020

Accepted: June 27, 2020

Published: June 30, 2020

Copyright $\odot 2020$ by author(s) and Scientific Research Publishing Inc. This work is licensed under the Creative Commons Attribution International License (CC BY 4.0).

http://creativecommons.org/licenses/by/4.0/

\begin{abstract}
This study was aimed at assessing soil erosion, climate variation and how climate has affected both the agro climatic and agro-ological zones of Kerio Valley basin. The basin faces challenges especially soil loss, due to the massive degradation that takes place in Kerio valley. Due to the increase in rainfall recently experienced in the area, most of the top soil has been carried away leading to excessive degradation of the valley, causing soil loss in the basin and subsequent deposition of the sediments in Lake Kamnarok which is an oxbow lake posing it to the threat of extinction. All these aforementioned factors, i.e. soil erosion, climate variation and land degradation have contributed to reduction of water storage capacity of the Lake. The main objective of this study was to assess the effects of soil erosion, climate variation on the basin and climate effect on agro-climatic and agro-ecological zones of the basin. Agro-climatic zones show how climate variability shapes agricultural landscape of an area while agro-ological zones show how agriculture affects the ecology of the basin. This includes the reduction of the lake size that has led to the disruption of the ecology of Lake Kamnarok and its environs, the major implications being the lake size reduction as the lake is proved to be a home for reptiles especially crocodiles. All these factors were finally assessed to determine their effect on water reduction capacity of Lake Kamnarok. The results depicted that the major factors that have caused changes in the basin and the Lake include heavy rainfall that has resulted in soil erosion and subsequent land degradation. These factors have eventually affected the agroclimatic and agroecological zones of the basin. This study integrated the use of Geographic Information System (GIS) and Remote Sensing (RS) to assess the areas with massive degradation and to quantify the amount of soil loss using Revised Universal Soil Loss Equation (RUSLE) model. It was concluded that the main factor that caused the changes in the agroclimatic and the agroecological zones was soil erosion which was influenced by climatic factors, i.e. rainfall and temperature.
\end{abstract}




\section{Keywords}

Agro-Ecological Zones, Food and Agriculture Organization, Geographic Information Systems, Remote Sensing, Land Use Land Cover

\section{Introduction}

\subsection{Background}

Sedimentation is the deposition of large particles into water bodies for example rock and soil particles. Degradation comes as a result of heavy rainfall on the highland areas that result in top soil being carried away and deposited in low terrain areas.

Baringo District is a dry area of lowland pasture on the floor of the Rift Valley in west central Kenya. It has long been portrayed as an erosion disaster region, a desert created by the inadequate husbandry of African pastoralists and their land ownership and management (Kiragu, 2013; Zende et al., 2018).

Different reports and news from media depict the area as a soil erosion prone zone with the walls of the Rift Valley most affected leading to sedimentation in the low regions. This therefore necessitated the need for this scientific research to quantify the soil loss rate of the area and recommended policy implications towards soil and vegetation conservation of the basin.

Land degradation occurs slowly and cumulatively and has long-lasting impacts on rural livelihoods who become increasingly vulnerable (Muchena, 2008). Adverse climatic conditions too can lead to the reduction of water capacities of lakes, reservoirs and dams.

In this research, RUSLE model was used to quantify sedimentation that occurred between the year 2004, 2011 and 2018 by quantifying the amount of soil loss for the epochs under investigation. RUSLE model factors that were used in this study are the R-factor (rainfall erosivity factor), the K-factor (soil erodibility factor), the C-factor (crop management factor), the P-factor (support practice factor) and finally the slope length factor.

\subsection{Objectives}

The objectives of this study were to: 1) Estimate annual soil loss of the catchment for the years 2004, 2011 and 2018 using RUSLE model 2) Analyze the climatic conditions of the catchment using the climatic factors (rainfall and temperature) 3) Establish the agroclimatic and agro-ological zones of the catchment.

\section{Materials and Methods}

\subsection{Study Area}

The study area (Figure 1) consists of a basin that is situated at the boarder of two counties, that is Elgeyo Marakwet and Baringo County. River Kerio flows 


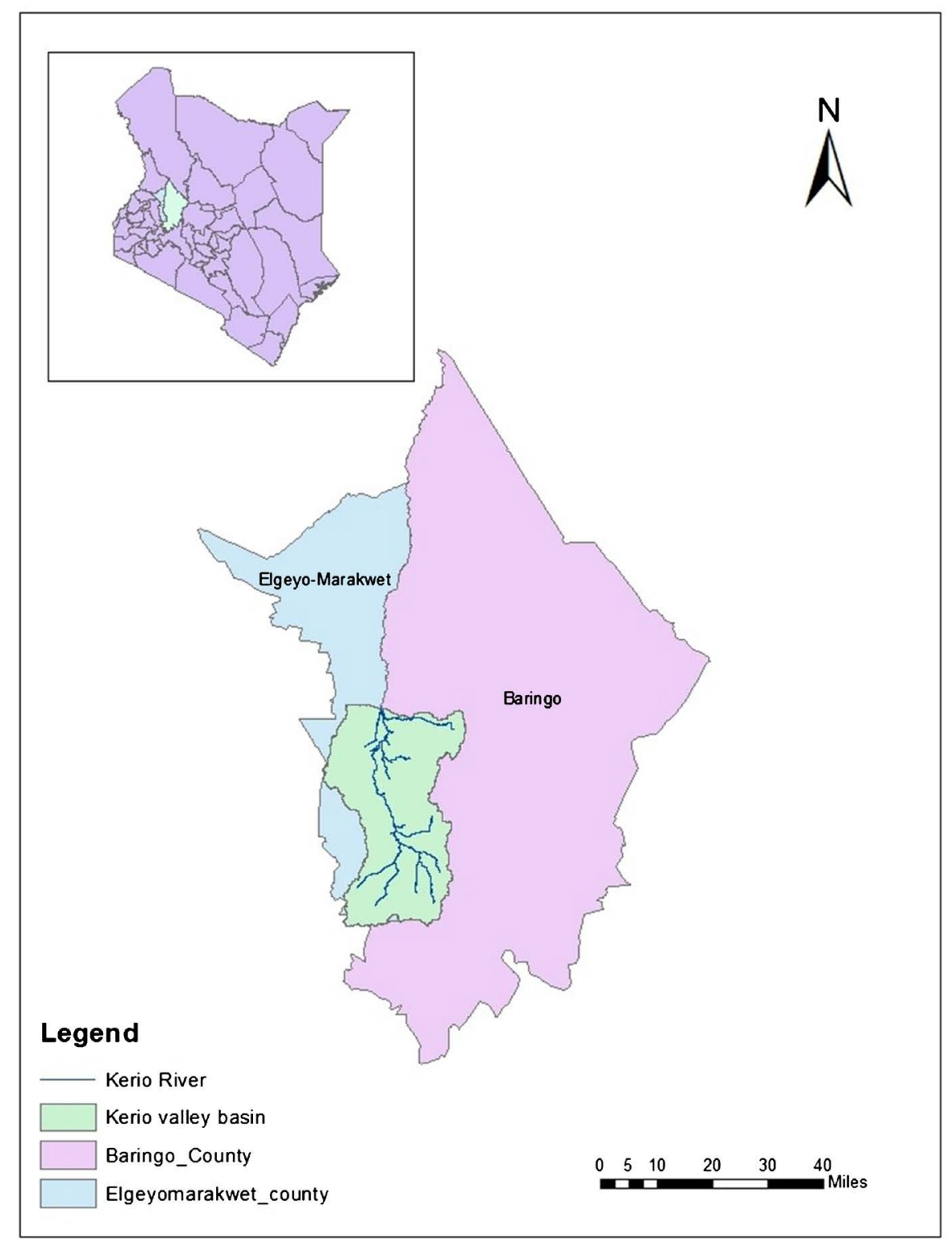

Figure 1. Study area.

northwards through the middle of the basin. The basin has an area of approximately 1785.5 square kilometers.

A DEM of the area was used to delineate the basin; sinks were then filled after which flow direction raster of the area was generated. The result was used to generate channels draining into the main stream that is Kerio River. Outflow point was defined which was later used to define the catchment. Half of the basin is situated at the lowlands while the other half is situated in the highlands.

\subsection{Data}

Landsat ETM satellite images for the years 2004, 2011 and 2018 were classified to generate Land use and Land cover maps. Landsat images were acquired from USGS website. Soil data was acquired from Kenya Agricultural and Livestock 
Research Organization (KALRO) where different soil types were represented in the data. Rainfall data for the years 2004, 2011 and 2018 was obtained from Chirps database. Soil moisture data and evaporation data were obtained from World Clim for the respective years under study. These datasets were used for this particular study. The SRTM DEM was downloaded from USGS website. For the rainfall and temperature, data for the clipped area of interest was extracted for further analysis. The rainfall and temperature data were of relatively high resolution.

\subsection{Methods}

For this research, first supervised classification was performed using ERDAS IMAGINE where five training classes were chosen comprising of: croplands, bare land, grassland, waterbodies and shrubs. Classification was done for the three years of interest, 2004, 2011 and 2018. Landsat ETM+ was used for this exercise. The image was first de-stripped to fill the gaps then mosaicked and finally the bands were layer stacked. The training classes were chosen and the classification carried out. Validation of the results was carried out using archived ground truth data for the years in question and supplemented with high resolution satellite imagery acquired within the periods under investigation.

Rainfall and temperature data were analyzed. Annual average rainfall and temperature was determined from the year 2004 to 2018. Further analysis was done for the specific years and statistics showing variation generated using Microsoft excel software.

Rainfall data and temperature data were then used to create the agroclimatic zones. In this case, the elevation and temperature values were used to make a linear regression equation and same case to evaporation and elevation. The outcome was put in a raster calculator and the output was a temperature map and an evaporation map. A ratio of evaporation to rainfall was done so as to get moisture availability map. Reclassification of both the temperature and the moisture availability map was done so as to obtain temperature zones and moisture zones. Fuzzy overlay method was then used for both the layers and the final output yielded the agroclimatic zones. This was done for the year 2004, 2011 and 2018.

Soil data and rainfall data was added to get the AEZ. In this case fuzzy overlay was done for the layers, that is rainfall, temperature and soil. Then multivariate clustering was done so as to delineate the AEZ. The zones were then named according to their climatic characteristics.

\section{Results and Discussion}

\subsection{Land Use \& Land Cover}

Supervised classification was performed using ERDAS IMAGINE 2015 software. Five Land use land cover classes were recognized: cropland, bare land, shrubs, water body and grassland. For the year 2004, a big percentage of the study area was under cropland compared to grassland and the bare land respectively (Figure 
2). The size of Lake Kamnarok in 2004 was found to be approximately 13 square kilometers.

2011 classification results depicted a slight reduction in acreage under cropland and increase in area under grassland. There was also increase in bareland depicted from the classified map shown in Figure 3. This may be attributed to increase in erosion leading to loss of vegetation and crop cover. It was also established that acreage under water reduced significantly and this may be attributed to deposition of sediments on the Lake.

According to 2018 classified map (see Figure 4) there was significant increase in area under grassland which may be attributed to increasing vegetation growth after soil deposition and sedimentation regimes especially on the lowland areas. Area under cropland reduced and this may be attributed to Land degradation hence reducing available area to be put under crop production.

\subsection{Soil Erosion}

Several models have been developed globally for the assessment of water-borne erosion (Lal, 2001), ranging from physical (Beasley et al., 1980; Yu et al., 1997), conceptual (Johanson et al., 1980; Viney \& Sivalapan, 1999), and empirical (Mitasova et al., 1996; Renard et al., 1997; Wischmeier \& Smith, 1978) models

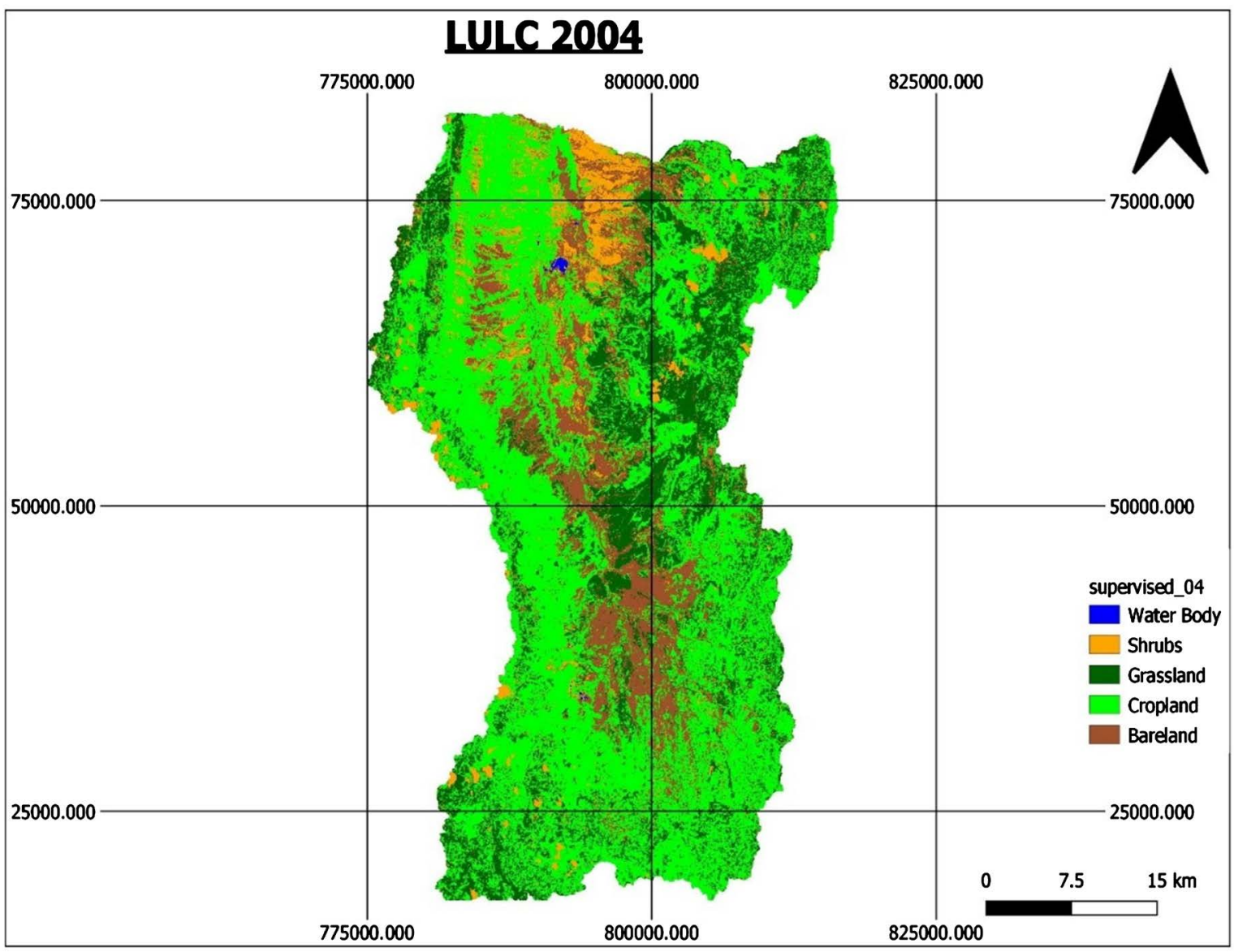

Figure 2. LULC 2004. 
M. K. Boitt et al.

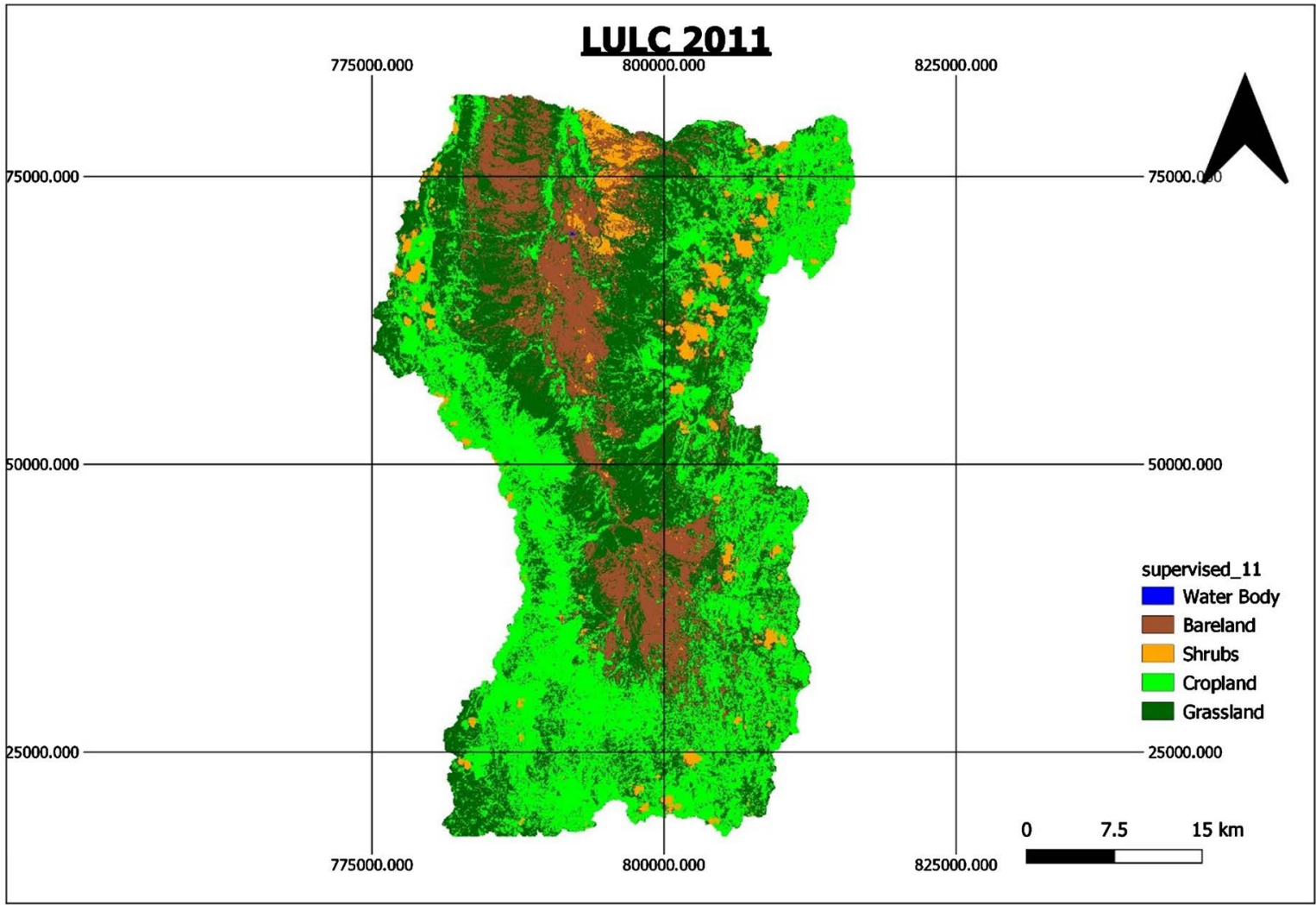

Figure 3. LULC 2011.

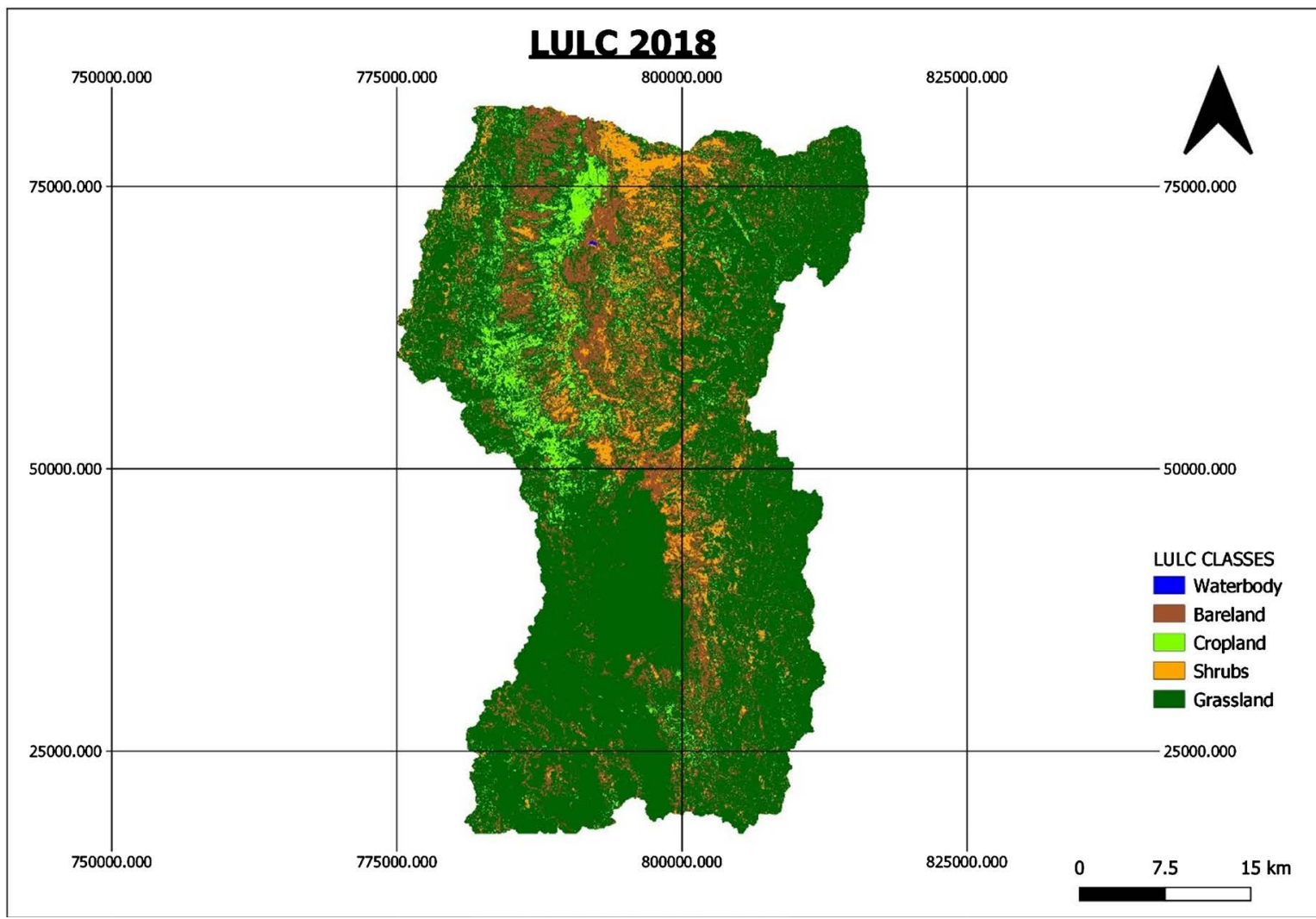

Figure 4. LULC 2018. 
(Rigaud \& Le Bot, 2013).

Empirical erosion models such as the Revised Universal Soil Loss Equation (RUSLE) provides a rather simple and yet comprehensive framework for assessing soil erosion and its causative factors. RUSLE considers rainfall $(R)$, topography $(L S)$, soil erodibility $(K)$, cover management $(C)$, and support practice $(P)$ as important factors affecting soil erosion. In the past few years, RUSLE has benefited tremendously from advances in geospatial technologies like Geographic Information Systems (GIS) and remote sensing (Rigaud \& Le Bot, 2013).

Amongst these models, RUSLE has proven to be the most frequently used computer-based model (Alexakis, Hadjimitsis, \& Agapiou, 2013) which provides a clear perspective for understanding the interaction of erosion and its causative factors (Xiao, Yang, Chen, \& Cai, 2015; Rigaud \& Le Bot, 2013).

RUSLE model was used to assess and quantify the total amount of soil. For RUSLE model (Figure 5) there are a number of factors that were used which are: $R$-factor. The rainfall erosivity factor is computed to show and express the amount of water amount and strength to carry away the top soil (Wischmeier \& Smith, 1978). This is a measure of erosive force and intensity of rain in a normal year. Hence the $R$ factor is directly affected by the changes in precipitation.

$R=-8.12+(0.562 * P)$ Method by: Hurni, H. (1985).

$P=$ mean annual precipitation $(\mathrm{mm})$.

$K$-factor: The soil erodibility was calculated using the method and formula given by:

$$
\begin{aligned}
K= & \{0.2+0.3 \exp +[-0.0256 S d(1-s i / 100)]\} *\{S i /(C l+S i)\} \\
& 0.3 *\{1-0.25 C /[C+\exp (3.72-2.95 C)]\} \\
& *\{(1-0.7 S N) /[S N+\exp (5.51+22.9 S N)]\}
\end{aligned}
$$

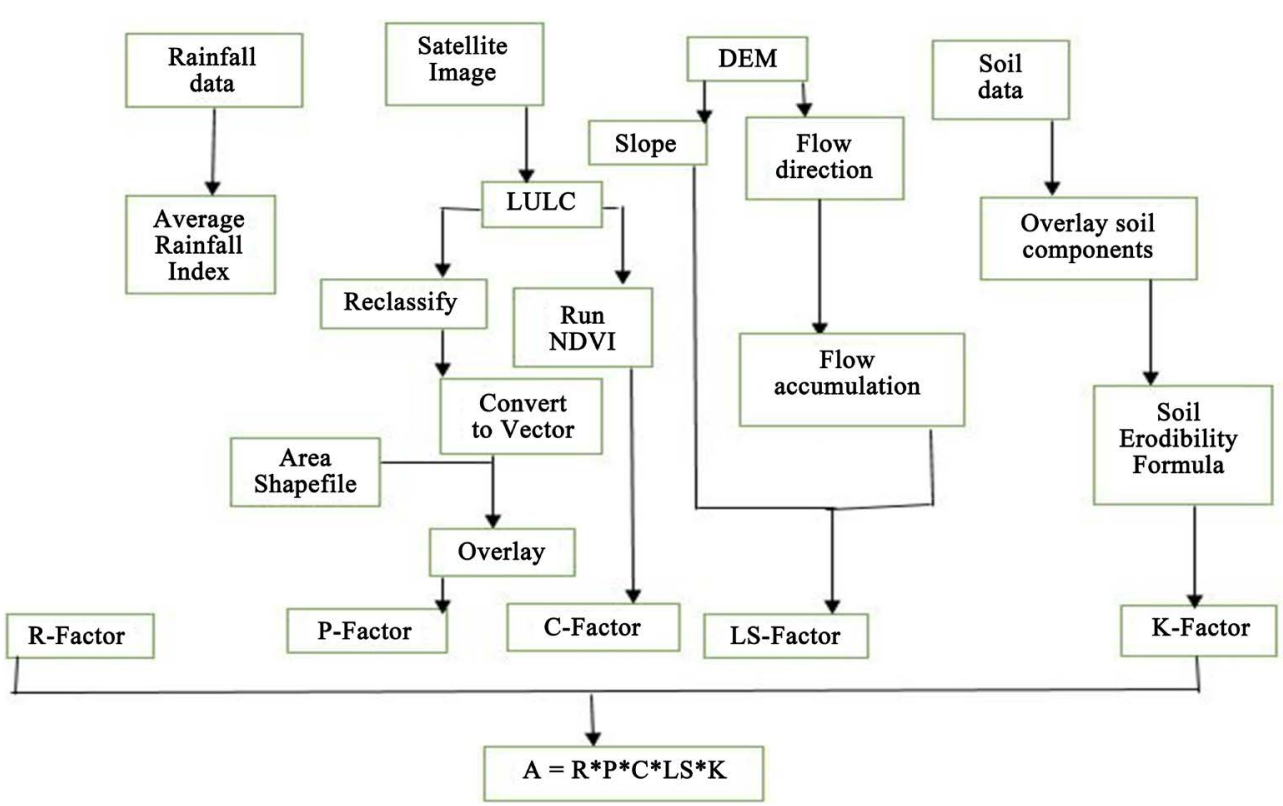

Figure 5. Flow chart of the RUSLE model. 
$S N=1-S d / 100, S d-$ Sand content (\%), Si-Silt content (\%), Cl-Clay content (\%), $C$-Organic carbon content (\%).

$L S$-factor: Slope length $(L)$ is the effect of slope length on erosion.

Slope steepness $(S)$ represents the effect of slope steepness on erosion. The effects of slope steepness have a greater impact on soil loss than slope length. Steeper the slope, the greater is the erosion.

The equation that was used was given by: Morgan \& Davidson 1991, where; $L$-Slope length in $\mathrm{m}$.

$S$-Percent slope.

$C$-factor: The first process in computing $C$, was the raster calculation of the normalized difference vegetation index (NDVI). The raster calculation was carried out in the BandCalc tool of the Semi-Automatic Classification Plugin (SCP).

The formula used for calculating NDVI for Landsat ETM is as follows:

$$
\mathrm{NDVI}=\frac{\mathrm{NIR}-\mathrm{RED}}{\mathrm{NIR}+\mathrm{RED}}
$$

$P$-factor: The conservation practice factor $(P)$ represents the ratio of soil loss by a support practice to that of straight-row farming up and down the slope and is used to account for the positive impacts of those support practices.

The general formula for the RUSLE model is:

$$
A=R * K * L S * C * P .
$$

where, $R$-Rainfall erosivity,

$K$-Soil erodibility,

$L S$-Slope length \& slope,

$P$-Support practice,

$C$-Cover management.

Figures 6-8 illustrate the soil erosion in the area. Since it is not justified that all the soils were carried away to the lake in the basin (Figure 9), Lake Kamnarok, hydrology analysis was done where flow direction and flow accumulation (Figure 10) was done on the area of interest so as to identify or depict areas with a high soil loss due to the flow accumulation and the results were represented in form of a map with low values starting from 100 and high values up to 196,000, with the high values majorly lying on the Kerio River that lies at the middle of the basin. The map is as shown.

\subsection{Climate Variation}

\subsubsection{Rainfall Analysis}

Being one of the factors of climate, assessment needed to be done for effective planning and conservation practice of the basin.

Rainfall analysis was done from the year 2004 to 2018 and the results were represented in form of a graph as shown.

Figure 11 shows annual average rainfall amounts of rainfall which increased from $1367.447917 \mathrm{~mm}$ in 2004 to 1575.46875 in 2011 and finally 1795.03125 in 2018 . 
M. K. Boitt et al.

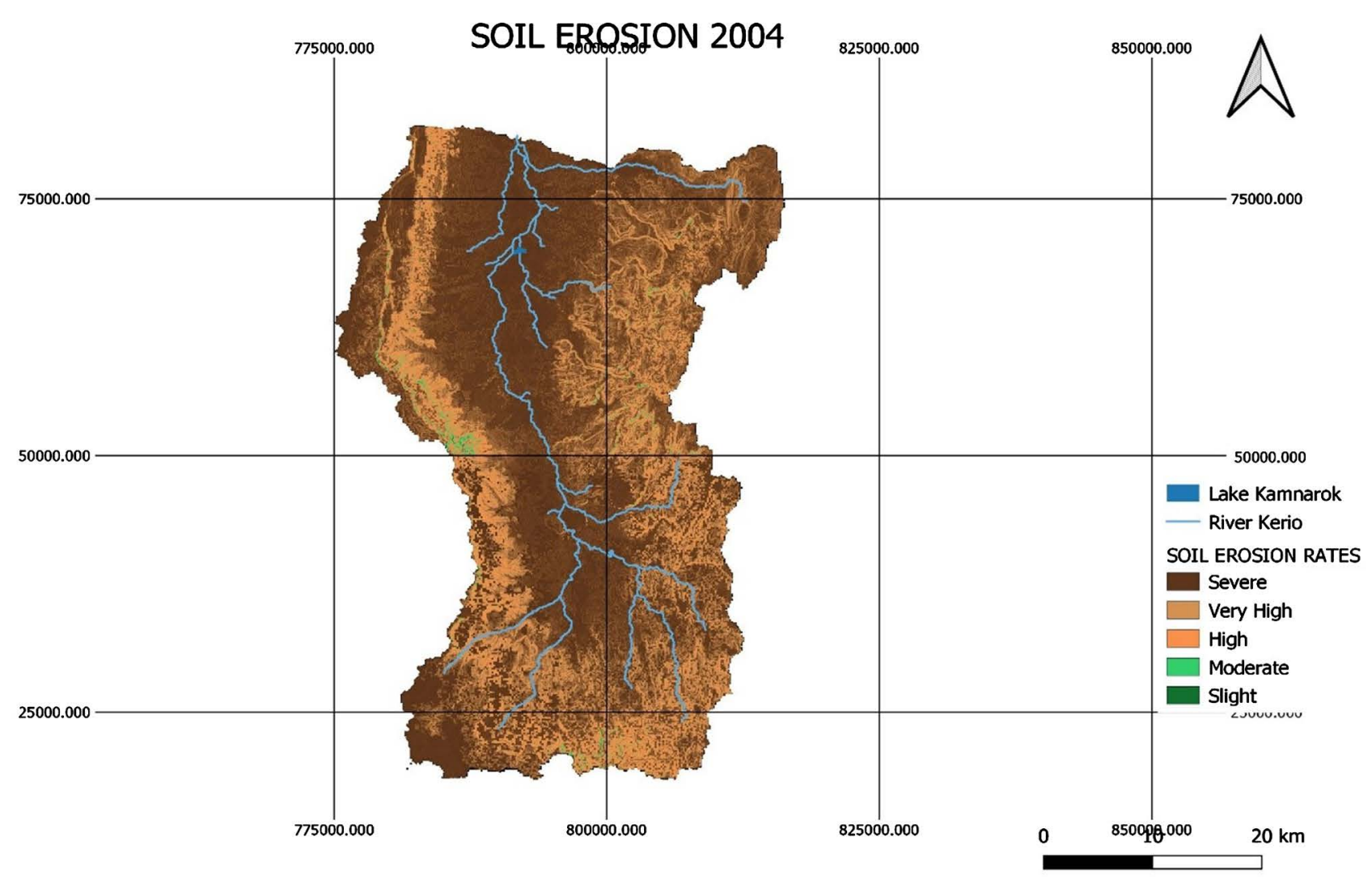

Figure 6. Soil loss for the year 2004.

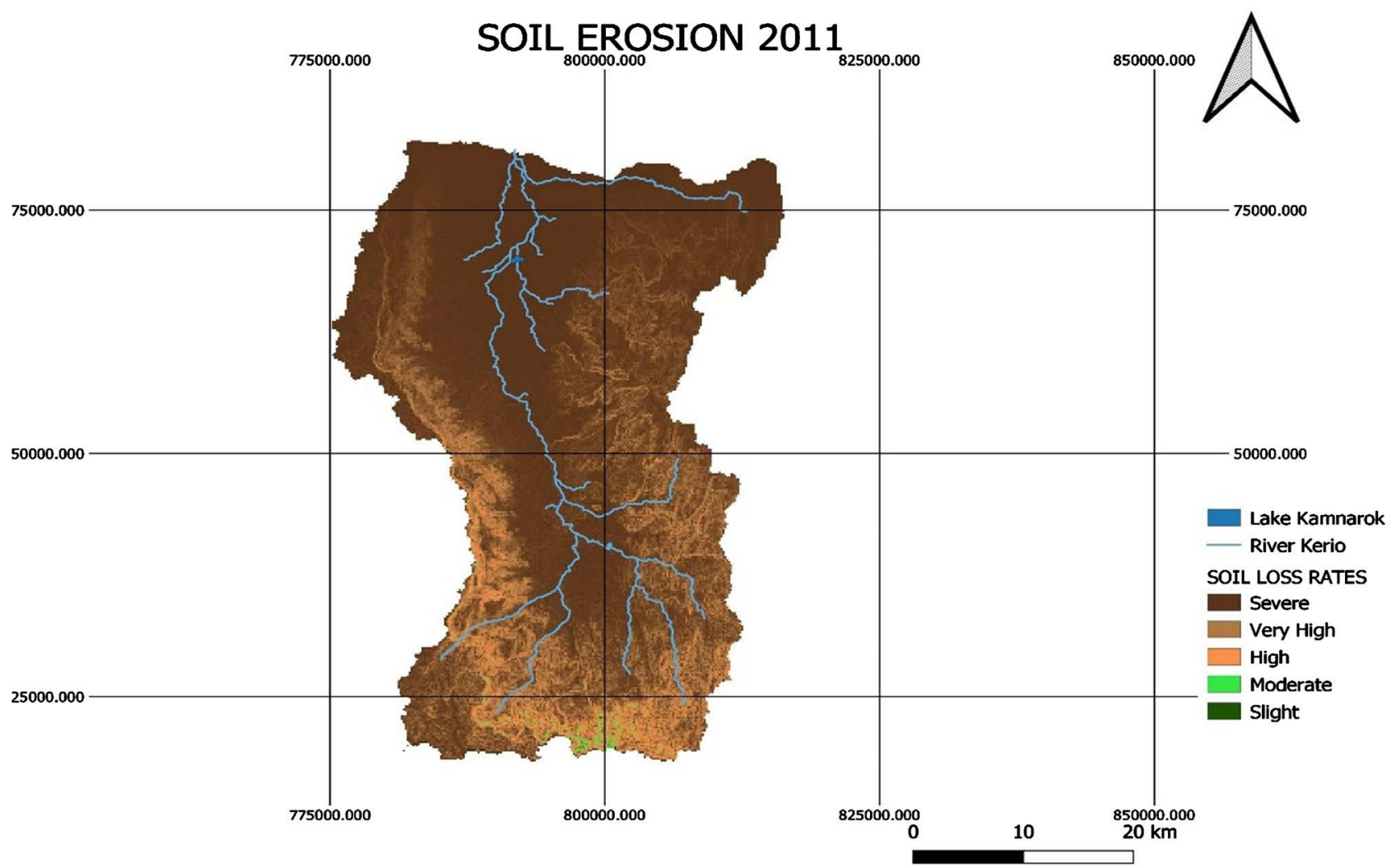

Figure 7. Soil loss for the year 2011. 


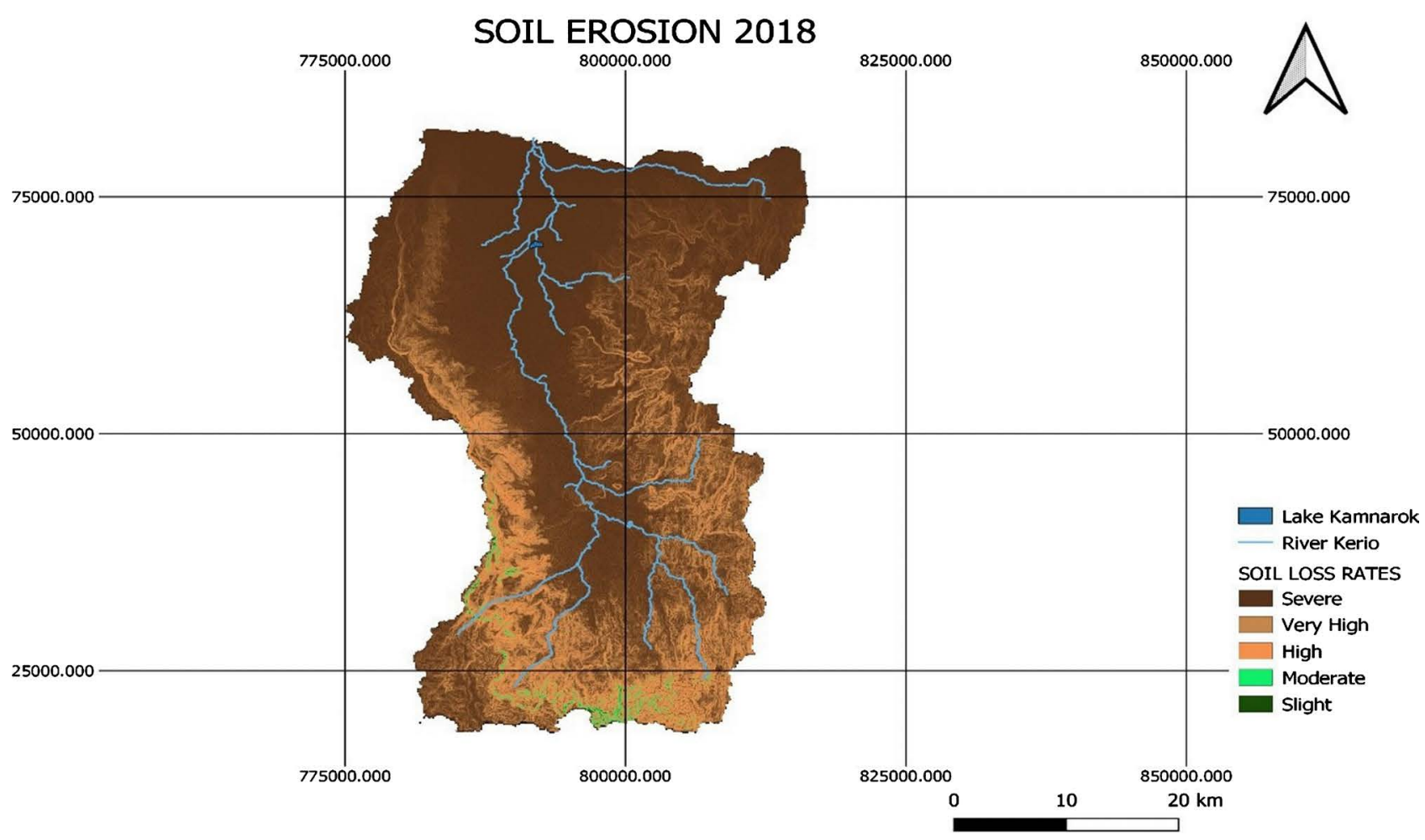

Figure 8. Soil loss for the year 2018.

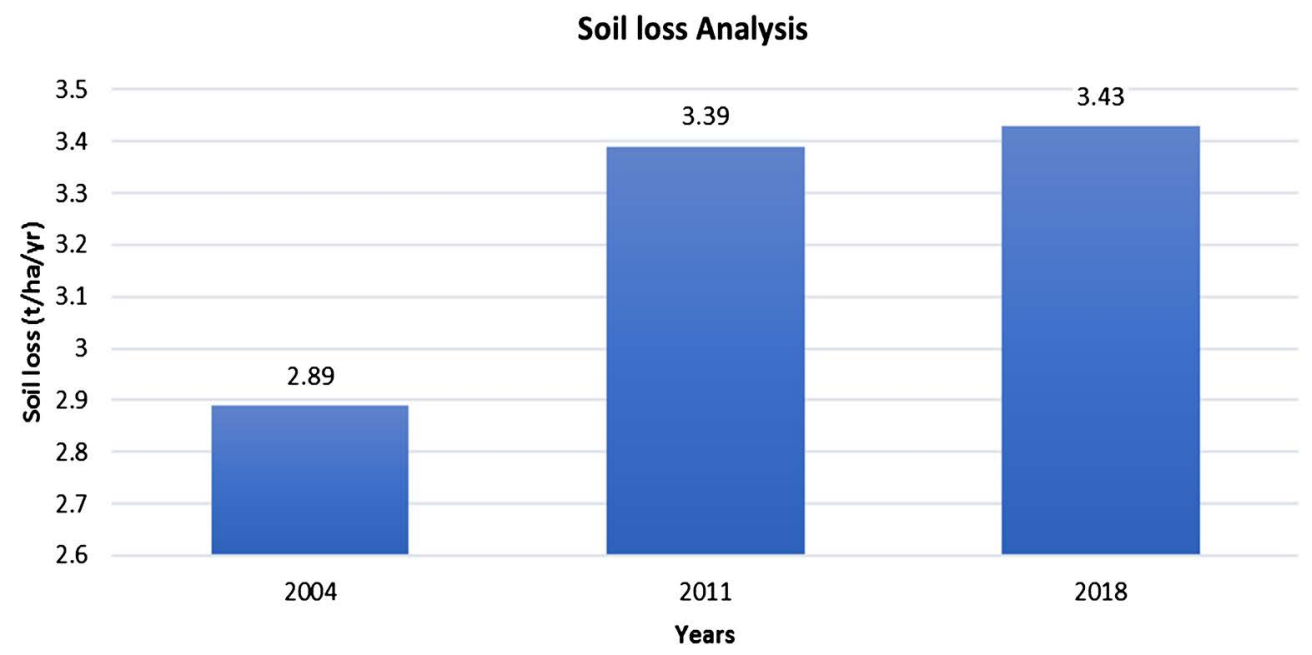

Figure 9. Soil loss analysis.

\subsubsection{Temperature Analysis}

Temperature analysis was also evaluated from the year 2004 to 2018 and it was seen that there was a slight but consistent decrease in temperature over the years (Figure 12). Annual temperature in 2004 was 29.7, in 2011 the temperature was 29.4 and in 2018 the temperature was 25.2 .

\subsection{Agroclimatic Zones}

The agro-climatic zones are specific combinations of moisture availability zones and temperature zones. The map recognizes that the major aspects of climate 
that affect plant growth are moisture availability and temperature. Figure 13 shows the agroclimatic zones for the year 2004.

Figure 14 shows the agroclimatic zones for 2011. It is evident that in 2011 the temperatures reduced while the moisture indices slightly increased. The semi-arid zones reduced in size due to the increase in rainfall between 2004 and 2011. The

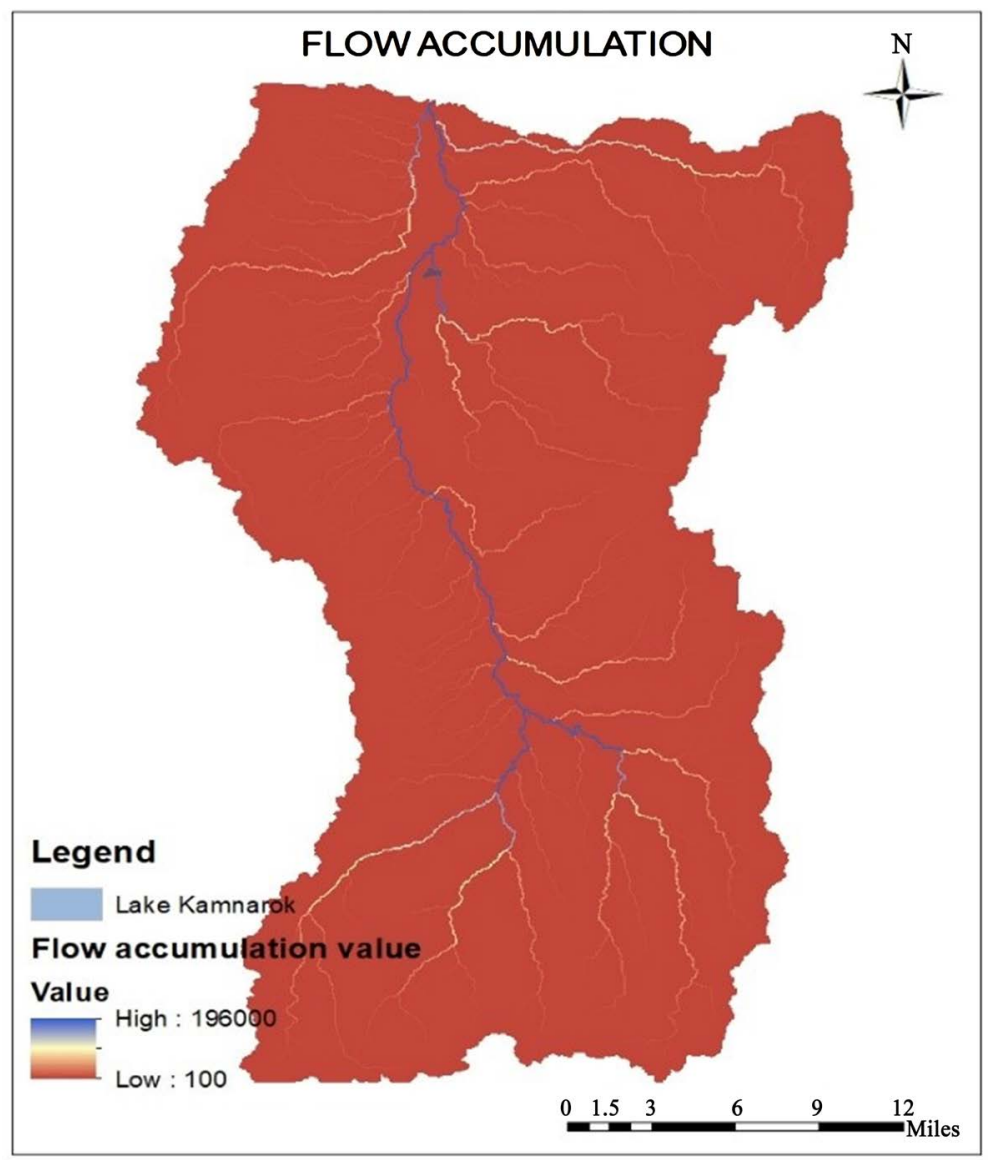

Figure 10. Flow accumulation.

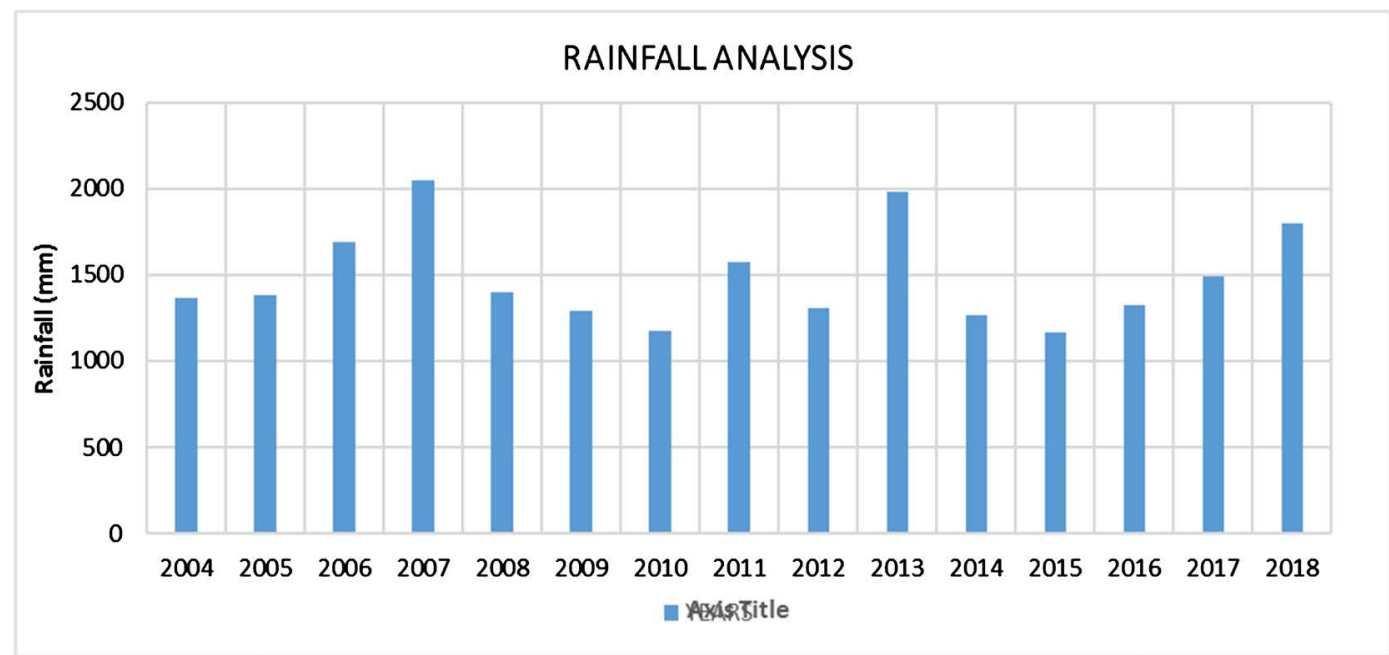

Figure 11. Rainfall analysis. 


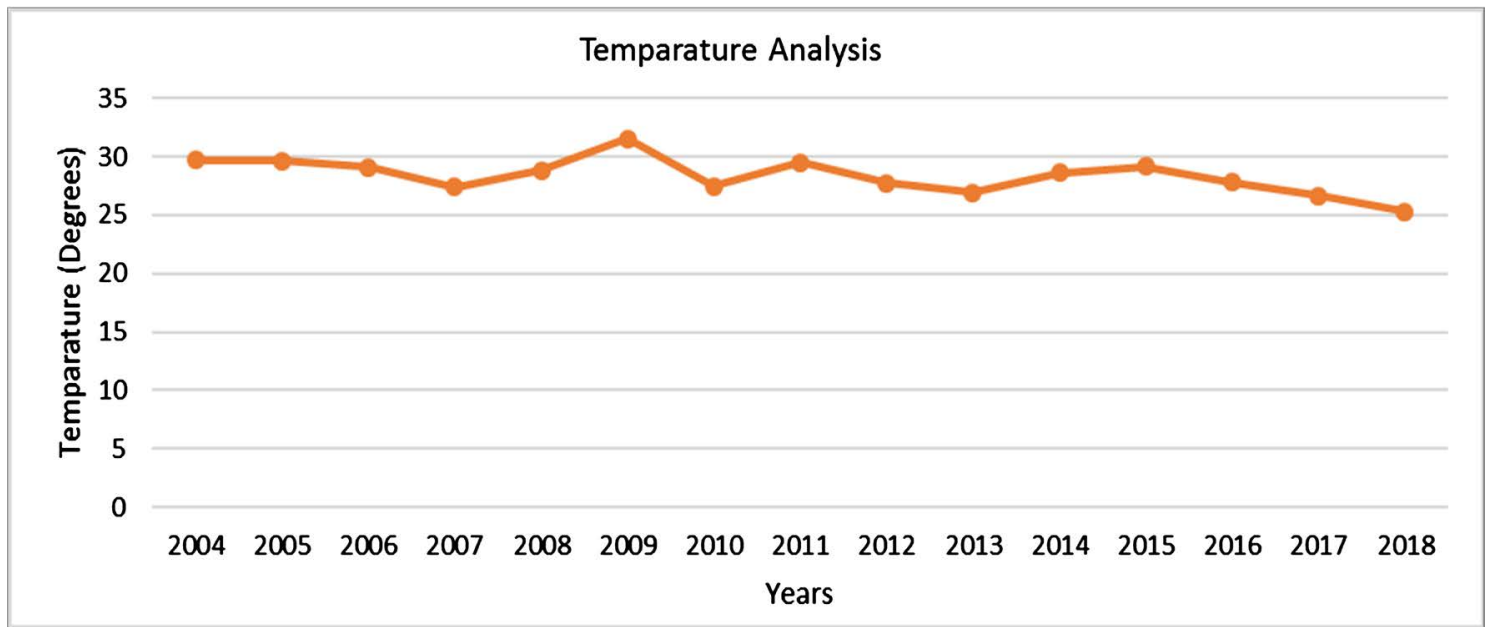

Figure 12. Temperature analysis.

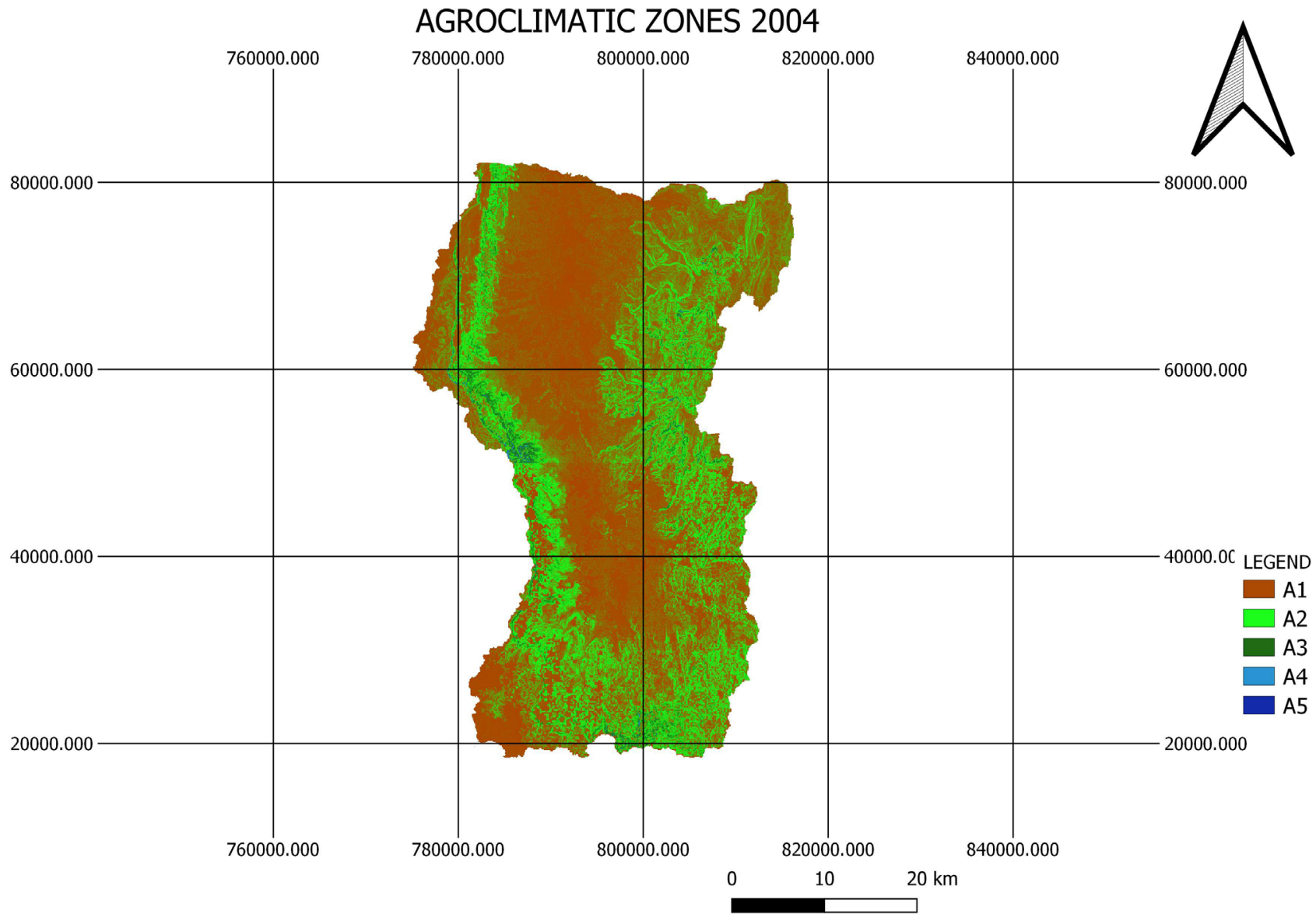

Figure 13. Agroclimatic zones for 2004.

semi humid zone is seen to increase due to the increase in rainfall and moisture index.

In 2018, the temperatures subsequently reduced while the moisture indices increased slightly (Figure 15). This is also due to the increase in rainfall in the region. The dry sub humid regions, the wet sub humid the semi humid and the 
M. K. Boitt et al.

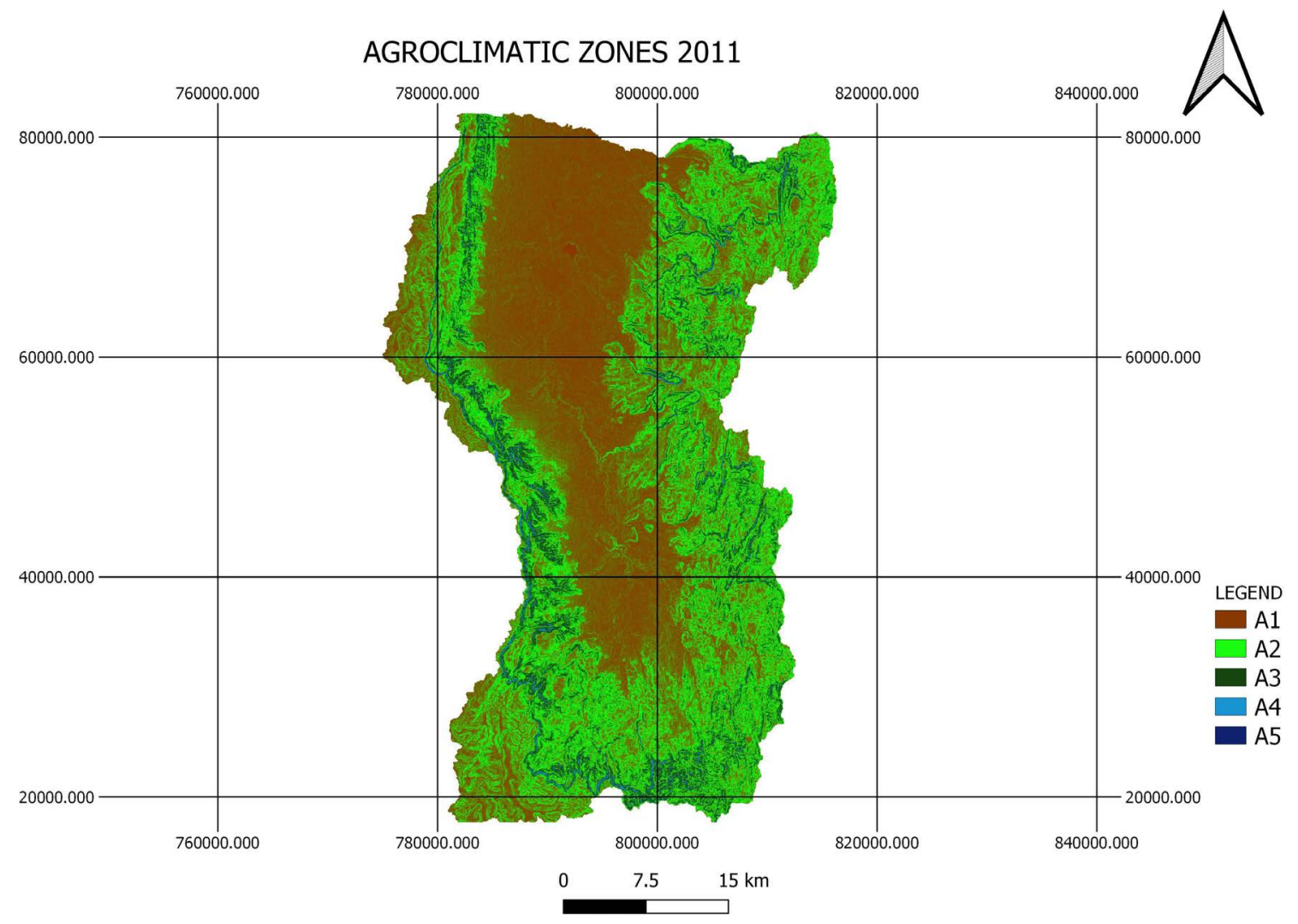

Figure 14. Agroclimatic zones for 2011.

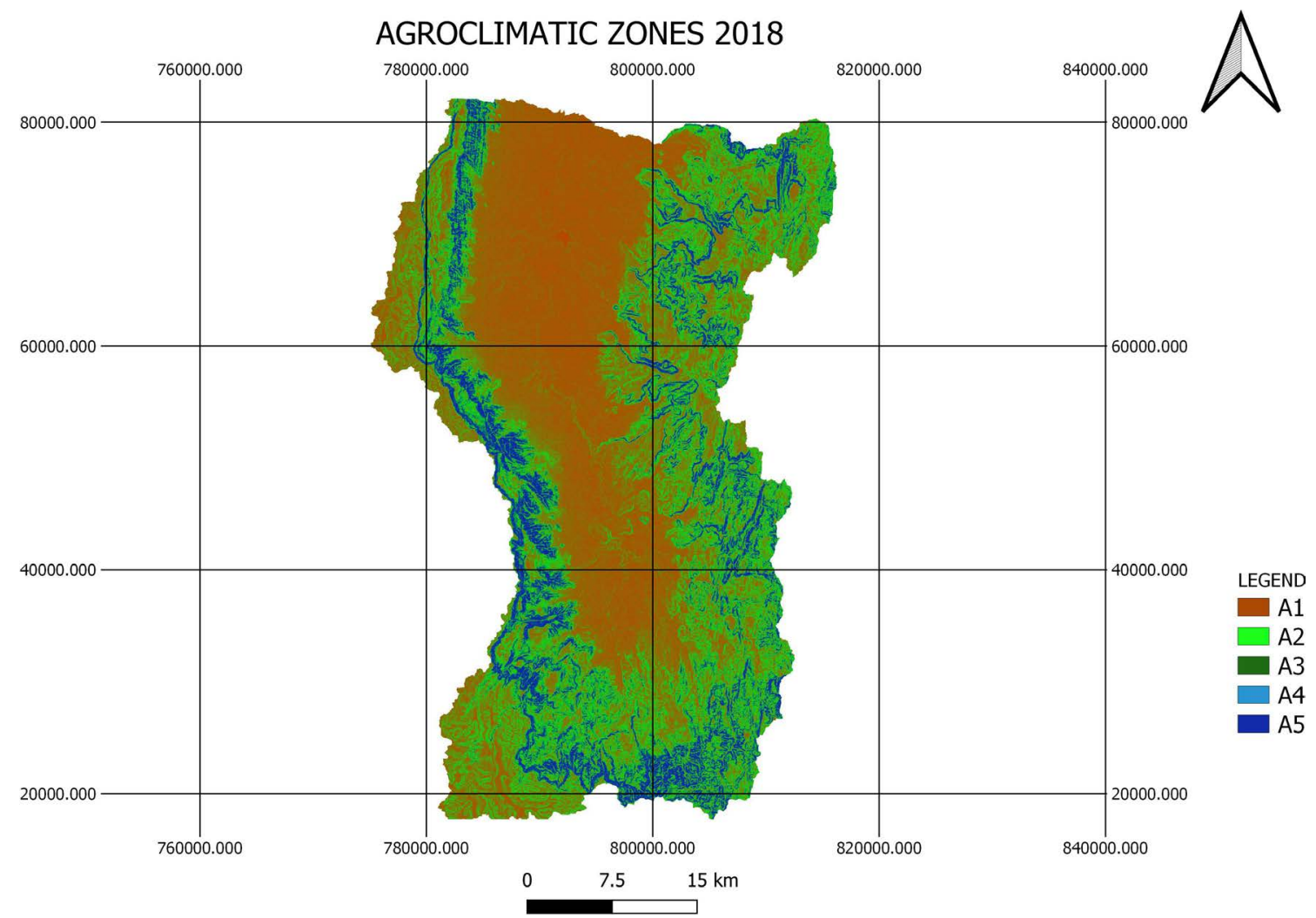

Figure 15. Agroclimatic zones for 2018. 
humid regions are the zones that are suitable for the growth of crops due to the high levels of moisture index.

\subsection{Agroecological Zones}

For the agro-ological zones, the changes that took place happened mainly on the zones that were classified for the region as shown in the results (Tables 1-3).

Multivariate clustering was used in this process mainly because multivariate clustering has been proven to be effective in delineating zonal boundaries depending on the characteristics of the layers that have been used as input datasets (Boitt et al., 2014). Suitability for each zone to agricultural practice was also determined and the results represented in Figures 16-18 and Tables 1-3.

In 2011, there was a lot of land degradation that took place due to the heavy rainfall in the study area hence carrying away the top soil. From the results, the upper midlands are seen to take domination.

Table 1. ACZ 2004

\begin{tabular}{ccccc}
\hline $\begin{array}{c}\text { Agroclimatic } \\
\text { zones }\end{array}$ & Temperatures $\left({ }^{\circ} \mathrm{C}\right)$ & Moisture index & Classification & $\begin{array}{c}\text { Suitability for } \\
\text { agriculture }\end{array}$ \\
\hline A1 & $27.0-29.5$ & $0.29-0.39$ & Semi-arid & Not suitable \\
A2 & $28.1-28.6$ & $0.36-0.39$ & Dry sub humid & Moderately suitable \\
A3 & $26.1-27.5$ & $0.42-0.45$ & Wet sub humid & Moderately suitable \\
A4 & $25.0-26.4$ & $0.45-0.49$ & Semi humid & Moderately suitable \\
A5 & $25.0-26.0$ & $0.49-0.52$ & Humid & Suitable \\
\hline
\end{tabular}

Table 2. ACZ 2011.

\begin{tabular}{ccccc}
\hline $\begin{array}{c}\text { Agroclimatic } \\
\text { zones }\end{array}$ & Temperatures $\left({ }^{\circ} \mathrm{C}\right)$ & Moisture index & Classification & $\begin{array}{c}\text { Suitability for } \\
\text { agriculture }\end{array}$ \\
\hline A1 & $27.1-29.7$ & $0.28-0.34$ & Semi-arid & Not suitable \\
A2 & $27.0-28.6$ & $0.40-0.34$ & Dry sub humid & Moderately suitable \\
A3 & $26.5-27.6$ & $0.46-0.40$ & Wet sub humid & Moderately suitable \\
A4 & $25.5-26.8$ & $0.46-0.40$ & Semi humid & Moderately suitable \\
A5 & $25.2-26.3$ & $0.46-0.52$ & Humid & Suitable \\
\hline
\end{tabular}

Table 3. ACZ 2018.

\begin{tabular}{ccccc}
\hline $\begin{array}{c}\text { Agroclimatic } \\
\text { zones }\end{array}$ & Temperatures $\left({ }^{\circ} \mathrm{C}\right)$ & Moisture index & Classification & $\begin{array}{c}\text { Suitability for } \\
\text { agriculture }\end{array}$ \\
\hline A1 & $29.8-29.2$ & $0.34-0.39$ & Semi-arid & Not suitable \\
A2 & $227.3-28.2$ & $0.39-0.44$ & Dry sub humid & Moderately suitable \\
A3 & $25.7-27.0$ & $0.44-0.49$ & Wet sub humid & Moderately suitable \\
A4 & $25.0-26.9$ & $0.44-0.49$ & Semi humid & Moderately suitable \\
A5 & $25.0-26.5$ & $0.49-0.52$ & Humid & Suitable \\
\hline
\end{tabular}




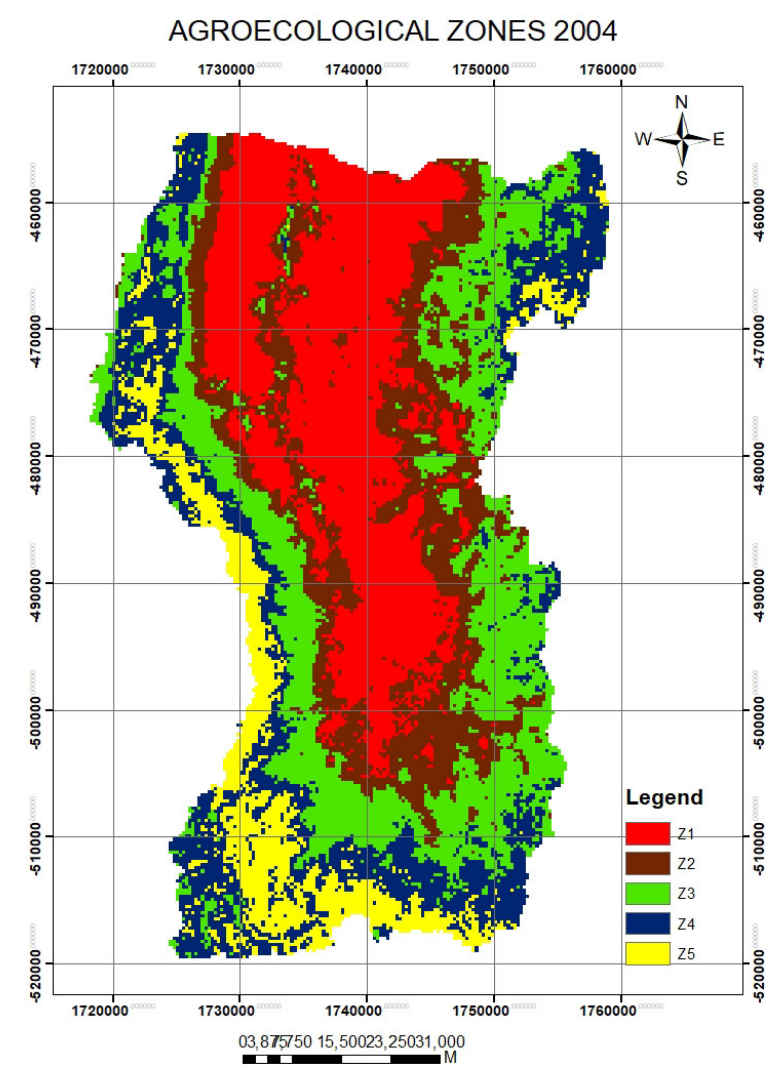

Figure 16. Agro-ecological zone for 2004.

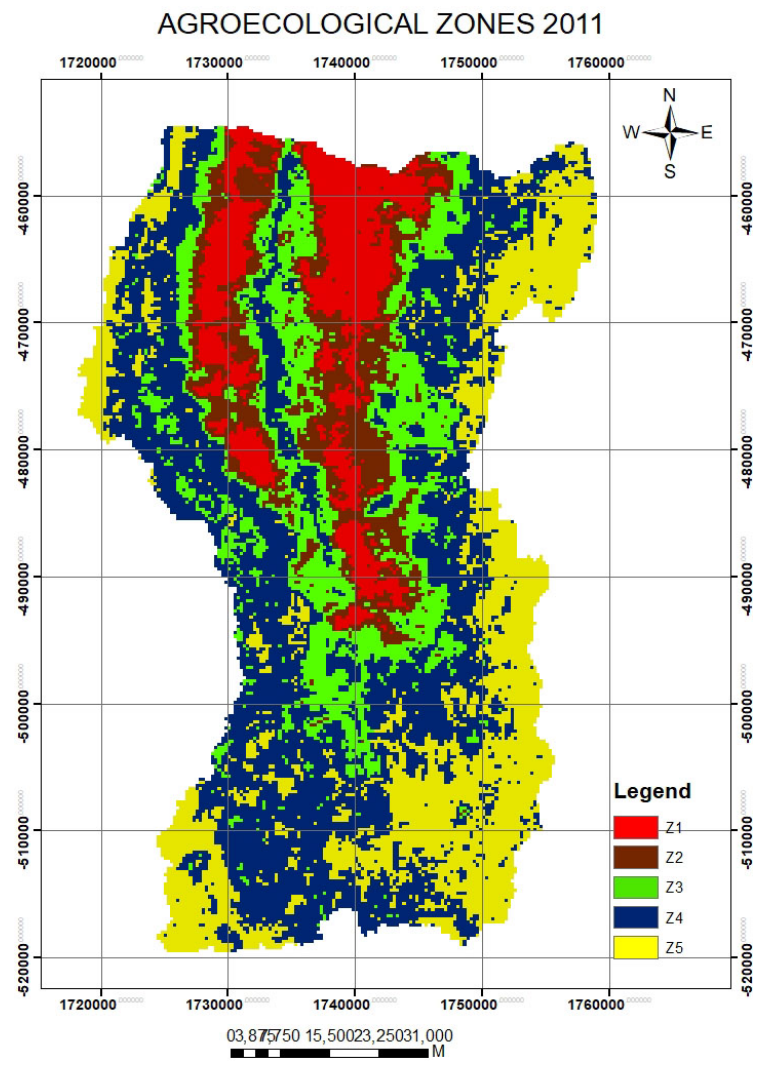

Figure 17. Agro-ecological zone for 2011. 
AGROECOLOGICAL ZONES 2018

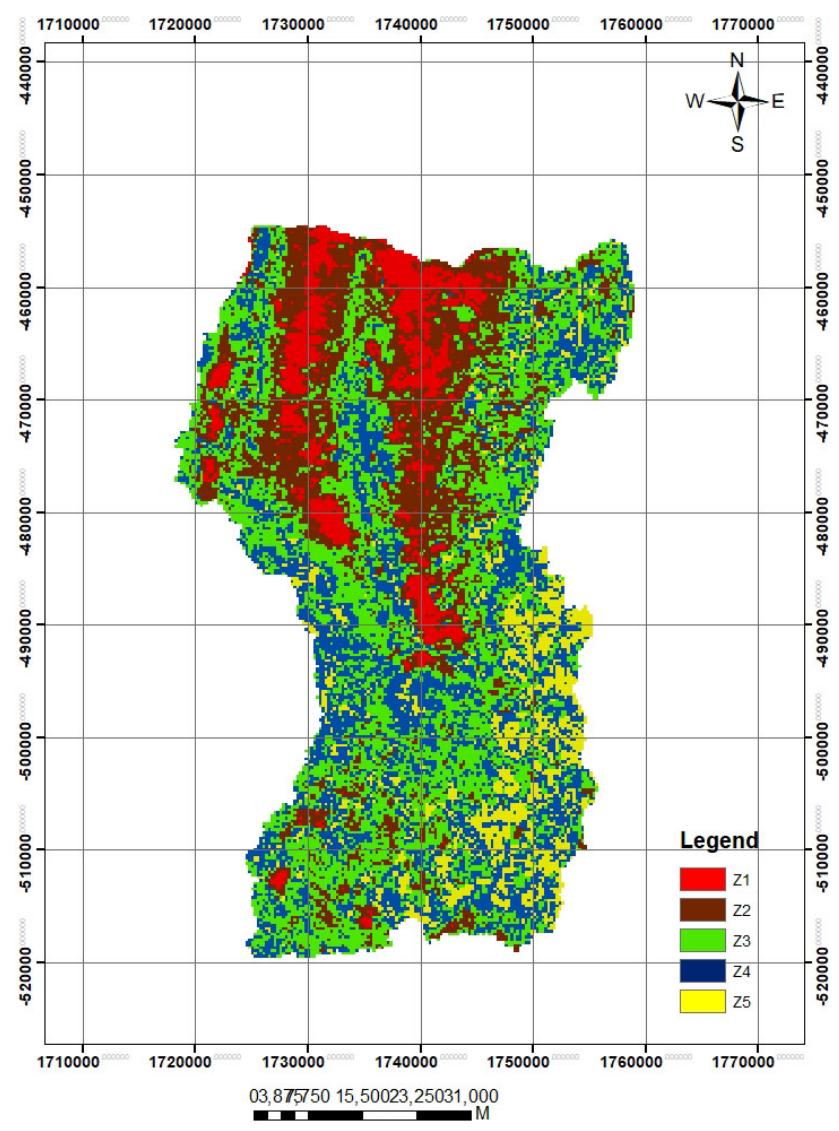

Figure 18. Agro-ecological zone for 2018.

In 2018, the lower midland zone is seen to occupy most parts of the basin. With the lowlands gradually decreasing in size from the year 2004 .

\section{Conclusion}

In this research, it is clear that one of the main factors that caused massive degradation of the basin is the heavy rainfalls that the region experienced between the year 2004 to 2018. Due to excessive runoff water, much of the top soil was carried away, thus ending up settling on the lake that is in that area, i.e. Lake Kamnarok causing a lot of silt deposition, and hence reduction of water capacity. The temperatures had minimal changes thus causing minimal effects to the region.

For the agroclimatic zones, it is evident that the area close to the lake is semi-arid receiving high temperatures and low rainfall while the highlands are, the valley or the escarpments having low temperatures and high rainfall hence contributing to the degradation of the valleys thus carrying away the top soil that settles on the lake. The highlands are found to be suitable for agricultural practice while the lowlands, that is the semi-arid region, are found to be less suitable for any agricultural practice due to the climatic conditions of that area.

The climatic conditions of Kerio valley basin affect the ecology, hence the changes that have taken place in the agro-ecological zones. Lower midland final- 
ly takes domination due to the degradation; hence it is evident that the grasslands occupy most parts that were filled with the croplands.

Moreover, it is evident that the major factors that have contributed to the changes taking place in the basin are the climatic changes that have led to land degradation and siltation of the lake hence reduction of its water storage capacity.

Lack of preventive measures and concerted efforts towards curbing land degradation in the study area will heavily impact on the wildlife community within the lake. The lake which is also a game reserve is a home to wildlife including elephants and variety of the reptile community. Protection of vegetation and plant community within the area is crucial for sound habitat of birds and other wildlife species in the reserve.

Human activities posing threat to the ecosystem including tree felling, charcoal burning, sand harvesting and grazing which also results in human-wildlife conflict should be discouraged and constructive alternative systems for livelihood improvement encouraged by the communities around and also the concerned government ministry.

This study therefore recommends timely soil and landscape conservational efforts in the wake of increasingly climate variation in order to establish ecological balance and protection of increasing reduction of species that were once common in the area. This study also recommends further research involving role of human-induced factors in contribution to land degradation of the basin.

\section{Acknowledgements}

We would like to thank the providers of the data and all that supported this project in providing relevant information for use during the analysis stages.

Our sincere appreciation goes to our University (JKUAT) and to GEGIS department in particular for providing a conducive environment, support and equipment during this research period and mostly throughout the study.

\section{Conflicts of Interest}

The authors declare no conflicts of interest regarding the publication of this paper.

\section{References}

Alexakis, D. D., Hadjimitsis, D. G., \& Agapiou, A. (2013). Integrated Use of Remote Sensing, GIS and Precipitation Data for the Assessment of Soil Erosion Rate in the Catchment Area of "Yialias" in Cyprus. Atmospheric Research, 131, 108-124. https://doi.org/10.1016/j.atmosres.2013.02.013

Beasley, D. B., Huggins, L. F., \& Monke, A. (1980). ANSWERS: A Model for Watershed Planning. Transactions of the ASAE, 23, 938-944. https://doi.org/10.13031/2013.34692

Boitt, M.K., Mundia, H. N., \& Pellikka, P. (2014). Modelling the Impacts of Climate Change on Agro-Ecological Zones-A Case Study. Geosciences Journal, 2, 172-179.

Hurni, H. (1985). An Ecosystem Approach to Soil Conservation. In S. A. El-Swaify, \& W. C. Moldenhauer (Eds.), Soil Erosion and Conservation (pp. 759-771). Ankeny: Soil 
Conservation Society of America.

Johanson, R. C., Davis, H. H. et al. (1980). Users Manual for Hydrological Simulation Program-Fortran (HSPF) (Vol. 80, No. 15). Environmental Research Laboratory, Office of Research and Development, US Environmental Protection Agency.

Kiragu, G. M. (2013). Assessment of Suspended Sediment Loadings and Their Impact on the Environmental Flows of Upper Transboundary Mara River, Kenya. Doctoral Dissertation, Juja: Jomo Kenyatta University of Agriculture and Technology.

Lal, R. A. T. T. A. N. (2001). Soil Degradation by Erosion. Land Degradation \& Development, 12, 519-539. https://doi.org/10.1002/ldr.472

Mitasova, H., Mitas, L., Brown, W. M., \& Johnston, D. (1996). Multidimensional Soil Erosion/Deposition Modeling. PART III: Process Based Erosion Simulation. Report for USA CERL. Urbana-Champaign, IL: University of Illinois.

Muchena, F. N. (2008). Indicators for Sustainable Land Management in Kenya's Context. GEF Land Degradation Focal Area Indicators. Nairobi: ETC-East Africa.

Renard, K. G. et al. (1997). Predicting Soil Erosion by Water: A Guide to Conservation Planning with the Revised Universal Soil Loss Equation (RUSLE). Washington DC: United States Government Printing.

Rigaud, E., \& Le Bot, A. (2013). Influence of Incidence Angle on Wear Induced by Sliding Impacts. Wear, 307, 68-74. https://doi.org/10.1016/j.wear.2013.07.015

Viney, N. R., \& Sivapalan, M. (1999). A Conceptual Model of Sediment Transport: Application to the Avon River Basin in Western Australia. Hydrological Processes, 13, 727-743. https://doi.org/10.1002/(SICI)1099-1085(19990415)13:5<727::AID-HYP776>3.0.CO;2-D

Wischmeier, W. H., \& Smith, D. D. (1978). Predicting Rainfall Erosion Losses: A Guide to Conservation Planning (No. 537). Department of Agriculture, Science and Education Administration.

Xiao, L., Yang, X., Chen, S., \& Cai, H. (2015). An Assessment of Erosivity Distribution and Its Influence on the Effectiveness of Land Use Conversion for Reducing Soil Erosion in Jiangxi, China. Catena, 125, 50-60. https://doi.org/10.1016/j.catena.2014.10.016

Yu, B., Rose, C. W., Ciesiolka, C. A. A., Coughlan, K. J., \& Fentie, B. (1997). Toward a Framework for Runoff and Soil Loss Prediction Using GUEST Technology. Soil Research, 35, 1191-1212. https://doi.org/10.1071/S97002

Zende, A. M., Rahul, A. P., \& Gopal, M. B. (2018). Sediment Yield Estimation and Soil Conservation Measures for Agrani River Basin Using Geospatial Techniques. Materials Today: Proceedings, 5, 550-56. https://doi.org/10.1016/j.matpr.2017.11.117 